\title{
Federalismo em vertigem, uma ascendência de problemas na administração pública?
}

Esta pesquisa é calcada na análise do sistema de governo brasileiro, buscando a arguição acerca da administração pública no domínio dos entes federados que compõe o Estado Federativo. Em um momento em que se almeja a democracia em seu melhor desempenho, cabe examinar a importância de aplicar a constituição vigente e respeitar os atos diligentes de organizar a distribuição de riquezas. No desdobramento da investigação, inquire-se a normativa constitucional, eficiência, prática e aderência perante as instituições e os governantes, assim como instigar a apresentação de falhas e proficiências no modelo federalista de um modo geral. Com vista na complexidade de levantar informações a respeito de um sistema político, os dados reunidos são norteados por meio da pesquisa bibliográfica, buscando a vertigem que assola o sistema federalista, bem como levar informações positivas que um Estado descentralizador pode oferecer. Apresenta-se, como fonte de estudo a proposta do novo Pacto Federativo apresentado recentemente pelo governo brasileiro e desenvolvido pelo ministro e economista Paulo Guedes. Ainda sem vigência, são grandes os desafios de encontrar uma solução administrativa que apresente a melhor forma de suprimir as ociosidades de uma federação. Por fim, a realização de procedimentos administrativos sérios fomenta o crescimento econômico, político e social de um Estado, logo, é necessário percorrer um sistema que apresente um meio termo na centralização e descentralização de poderes.

Palavras-chave: Federalismo; Administração; Entidades; Municípios.

\section{Vertigo Federalism, an ascendancy of problems in public administration?}

\begin{abstract}
This research is based on the analysis of the Brazilian government system, seeking the question about public administration in the domain of federated entities that make up the Federative State. At a time when democracy is aiming for its best performance, it is necessary to examine the importance of applying the current constitution and respecting the diligent acts of organizing the distribution of wealth. In the unfolding of the investigation, inquire about the constitutional norms, efficiency, practice and adherence to institutions and government officials, as well as instigating the presentation of flaws and proficiencies in the federalist model in general. With a view to the complexity of collecting information about a political system, the data gathered is guided by bibliographic research, looking for the vertigo that plagues the federalist system, as well as bringing positive information that a decentralizing state can offer. The proposal for the new Federative Pact recently presented by the Brazilian government and developed by the minister and economist Paulo Guedes is presented as a source of study. Still in force, the challenges of finding an administrative solution that presents the best way to suppress idleness in a federation are great. Finally, the realization of serious administrative procedures fosters the economic, political and social growth of a State, therefore, it is necessary to go through a system that presents a middle ground in the centralization and decentralization of powers.
\end{abstract}

Keywords: Federalism; Administration; Entities; Counties.

Topic: Gestão Pública

Reviewed anonymously in the process of blind peer.
Received: 04/04/2021

Approved: 06/06/2021
Geová Farias de Gois (iD)

Universidade Federal de Alagoas, Brasil http://lattes.cnpq.br/7346686666126445

http://orcid.org/0000-0002-3225-3999 geovafarias@bol.com.br

Natallya de Almeida Levino (id

Universidade Federal de Alagoas, Brasil

http://lattes.cnpq.br/2495024004949828

http://orcid.org/0000-0002-1215-3798

natallya.levino@feac.ufal.br
Referencing this:

GOIS, G. F.; LEVINO, N. A.. Federalismo em vertigem, uma ascendência de problemas na administração pública?. Revista Brasileira de Administração Científica, v.12, n.2, p.124-135, 2021. DOI: http://doi.org/10.6008/CBPC2179-684X.2021.002.0011 


\section{INTRODUÇÃO}

A administração pública regida pelos Entes Federados deve obedecer aos princípios dispostos na carta da Constituição Federal: "A administração pública direta e indireta de qualquer dos Poderes da União, dos Estados, do Distrito Federal e dos Municípios obedecerá aos princípios de legalidade, impessoalidade, moralidade, publicidade e eficiência" (BRASIL, 1988). Sendo assim, dando ênfase ao princípio da eficiência, a organização dos entes que compõe a federação deve ser extremamente rigorosa quanto ao seu comportamento na administração. Pelo fato das nossas entidades federativas serem indissolúveis, previsto também na constituição, a diversidade é respeitada no momento em que se determina à autonomia das mesmas.

De forma geral, a administração pública no sistema de federalismo brasileiro é orientada com os atos jurídicos, onde muitas vezes tais decisões ultrapassam o interesse público e passam a dar supremacia ao interesse particular. Sendo assim, um desenvolvimento organizacional deve sustentar as relações internas. Vale também ressaltar o importante esforço de manter a harmonia entre as associações sociais, ou seja, aquelas de caráter público ou de origem pública com as instituições.

Diante das diversas maneiras de conseguir um equilíbrio, destaca-se as ações do Estado na tentativa de descentralizar o sistema proporcionalmente a necessidade da população. Mecanismos de soluções de problemas econômicos e sociais são implantados com frequência no federalismo, com o objetivo de testar qual a melhor solução para as falhas que norteiam o sistema, as primeiras reformas no plano diretor do Estado brasileiro se deu em 1995 no governo de Fernando Henrique Cardoso, onde seguindo o processo de modernização a administração passou a se adaptar (CHIAVENATO, 2018). A importância de estudar e colocar em prática o federalismo brasileiro associando-o ao tema do constitucionalismo é de extrema importância pois carecerá a organização estatal e supremacia da legalidade (EVANS, 2001).

De fato, é necessário saber relacionar o sistema de governo atual com os princípios constitucionais vigentes e não atuais, pois, dessa forma junta-se um arcabouço de questionamentos que irão refletir na política do Estado, tais perguntas sempre se baseiam na característica de poder: "quem governa, como se governa e quem deveria governar" (EVANS, 2001). Logo, essas modificações e decisões suscitam mudanças em todo âmbito do Estado, seja ele econômico, político e administrativo, levando em consideração sempre o interesse da coletividade.

\section{METODOLOGIA}

A metodologia utilizada apresenta uma pesquisa qualitativa e usa como mecanismo de informações os fragmentos de dados para complementar uma total arguição, usando exemplos para facilitar a compreensão de uma maneira sistemática baseado em hipóteses construídas ao longo da pesquisa (GIL, 2017), adentrando também no levantamento bibliográfico, procurando está por dentro de toda conjectura de conhecimento possível (LAKATOS et al., 2017). Logo, foram consultados livros, artigos, sites de cunho vinculativo público e gravações orais. 
A análise dos dados dispõe de uma forma mais abrangente onde o apoio está nos textos narrativos e instrumentos, assim como as mais variadas formas de coletar dados, tendo em vista que a congruência dos fatos que se torna suscetível a modificações com o objetivo de obter ideais abrangentes (GIL, 2017). Podese analisar como instrumento a Constituição Federal, que no estudo em questão é o principal fator a ser seguido na primazia da administração pública e, por conseguinte a relação do estudo com as diversas fontes de ideias.

Devido posto em pauta um problema, que se caracteriza pela administração pública brasileira a luz do sistema federativo vigente, atribui-se um raciocínio hipotético-dedutivo com objetivo de chegar em hipóteses solucionadoras do problema. Conforme citado acima, a propensão de assertivas e erros é normal, visando sempre a posteriori a melhor maneira de resolver a questão.

A pesquisa tem a natureza aplicada, pois é dotada de fins práticos com o objetivo de "solução de problemas específicos" (PRODANOV et al., 2013). Devido as diversas questões levantadas ao longo do artigo, por exemplo, a hipótese dos municípios com baixa arrecadação poderem se auto sustentar com o sistema agrícola.

Como instrumento de levantamento informativo, a pesquisa foi montada a partir de livros, artigos e notícias em sites de natureza pública. Tais fontes são importantes para esse tipo de pesquisa, pois, sendo um tema contemporâneo, existe a necessidade de se basear em dados presentes. A respeito das áreas que 0 estudo abrange, administração, direito e economia, a escolha da literatura preenche a necessidade de encontrar conceitos que fundamentem o estudo.

\section{Dos fundamentos do federalismo, descentralização e administração}

O sistema de governo adotado pelo Brasil é o federalismo, logo, essa forma de Estado é descentralizada, ou seja, pressupõe-se que a política administrativa do Estado não se concentre em apenas uma unidade. "É a forma de Estado na qual existe descentralização no exercício do poder político, estando este pulverizado em mais de uma entidade política, todas funcionando como centros emanadores de comandos normativos e decisórios" (MASSON). Pode-se dizer que as competências são distribuídas entre as organizações para constituir a essência da descentralização.

Compreender este modelo é saber que a autonomia das entidades é ordenada conforme disposto o modelo federativo. Como bem nos assegura Chiavenato (2018), a ciência administrativa utiliza-se do aparelhamento estatal para organização conforme o interesse da população, nesse contexto fica claro que o objetivo é oferecer diversos cargos para melhorar a qualidade de vida do cidadão e consequentemente manter a economia do país girando com eficiência e celeridade.

Conforme explicado acima conceitos que são colocados de encontro com os dispositivos normativos vigentes, nota-se que nem sempre a eficiência é alcançada. É necessário organizar e antecipar táticas e envolvê-las em uma 'formalidade' para que se tenha o maior aproveitamento possível das situações. Logo, é sinal de que há, enfim, algumas incoerências administrativas, como por exemplo a proposta do novo pacto federativo de unir municípios com baixa arrecadação para corrigir o modelo atual de maior concentração 
financeira na união. Logo, os problemas surgem quase sempre em uma proposta de boa intenção. Então Oliveira Junior et al. (2018) comentam que os municípios devem agir de forma independente a sua administração, de forma que possa respeitar e seguir as competências atribuídas pela Constituição Federal.

Observa-se como um gasto crescente para regular verbas destinadas as entidades, o crescimento populacional. Partindo da entidade com a administração menos burocrática, para assim entender o funcionamento geral, reveste-se sobre os municípios brasileiros a concentração de mais da metade dos habitantes que residem no país, cerca de 120,7 milhões, dados levantados pelo IBGE. Conforme Fernandes et al. (2015), o governo federal tem falhado miseravelmente ao longo da promulgação da constituição acerca de administrar papeis tais como: criações de novos municípios e políticas públicas. $\mathrm{O}$ autor deixa claro que há de existir um planejamento minucioso da manutenção estatal, via de regra a disparidade que existe entre o governo central com os Estados e Municípios.

Destarte, o aparelhamento (sentido organizacional usado por Chiavenato) estatal está intrinsecamente ligado com a organização das entidades, de modo a não suprimir a autonomia dos mesmos, pois, a tomada do equilíbrio deve-se a estrutura bicameral do Congresso Nacional, onde o Senado Federal e a Câmera dos Deputados têm a função de legislar em âmbito nacional. "Entende-se por aparelho do Estado a administração pública em sentido amplo, ou seja, a estrutura organizacional do Estado" (CHIAVENATO, 2018). Desta forma, conforme mencionado pelo autor o aparelhamento é importante para a necessidade de organização, havendo limites para que a descentralização não passe a se tornar centralização.

Logo, a descentralização foi pensada a favor dos municípios como fonte de democracia por ser um grande sistema de participação popular:

Essa descentralização de baixo para cima teve como contrapartida a ampliação significativa das transferências voluntárias federais em favor dos municípios, em detrimento das unidades estaduais. A força do município estimula eleições municipais das mais concorridas, contribuindo para dinamizar e oxigenar a democracia brasileira. Emerge, portanto, no Brasil um federalismo de ideário autenticamente republicano. (CASTOR, 2008)

O autor deixa claro que o sistema de organização federalista deve manter uma constância no modus operandi de sua manutenção. Ora, em tese uma federação contínua, com aspectos que não mudam, geralmente tende a regredir ou ficar na mesma, porque a manutenção do aparelho estatal deve acompanhar a sociedade e o contexto histórico. Conforme Chiavenato (2018) a reforma do aparelho infere diretamente na melhora para a população, como também a manutenção em órgãos não estatais que são subsidiadas pelo Estado. Prontamente, conforme explicado acima, consequências fiscais relatadas pelo Estado são uns dos motivos para se tomar decisões de privatizações, por exemplo, a empresa siderúrgica USIMINAS, antes estatal que na década de 80 após um recesso econômico se tornou a primeira empresa a ser privatizada.

O rigor técnico é necessário em pautas restritas, entretanto, a população nem sempre é dotada de intelectualidade no que tange os assuntos de política, nesse aspecto seria importante transmitir para o público algo menos formalista. Conforme é citado acima a realidade é a desmotivação do público em cobrar a manutenção estatal, justamente pela complexidade com que é passada os documentos reguladores.

Portanto o sistema federalista deve ser alvo de reformas, excepcionalmente modificações administrativas, visto que a federação é possuidora de auto-organização e autoadministração: 
O paradigma gerencial contemporâneo, fundamentado nos princípios da confiança e da descentralização da decisão, exige formas flexíveis de gestão, horizontalização de estruturas, descentralização de funções, incentivos à criatividade. Contrapõe-se à ideologia do formalismo e do rigor técnico da burocracia tradicional. (CHIAVENATO, 2018)

Os municípios que desempenham grande importância administrativa e política nesse sistema, pois é detentor de grande parte da população como será mostrado nos tópicos adiante, ganharam autonomia para auto sustento e criação de leis permitidas pela Constituição. Castor (2008) comenta que os municípios começam a cria a responsabilidade de gastos como: "serviços públicos, com a folha de pagamento, com a aquisição de bens, com a contratação de terceiros para a execução de serviços e outros empreendimentos necessários para consecução de seus objetivos".

Esses dados revelam muito mais do que uma noção simples de federalismo, toca-se no ponto chave do sucesso desse sistema em um país que se diz descentralizador. A Administração Pública é de fato um assistente mensurador da definição de Estado modelador. A legitimidade de manutenção conferida pela Constituição às Entidades Federativas também pertence ao povo, dado que o Estado tem obrigação de conferir a individualização no que diz respeito a direitos e deveres (DURKHEIM, 2016).

\section{Proposta de mudança no pacto federativo brasileiro}

Introduz a partir de agora a análise de duas importantes mudanças com a PEC no 188 de 2019, a priori é essencial pôr em destaque a necessidade que o Estado tem de experimentar propostas diferentes visando a mutualidade das entidades. Este capítulo será baseado na análise da transferência de verba da união para os Estados e Municípios e a extinção de alguns municípios com menos de cinco mil habitantes. A necessidade de mudanças orçamentarias vão de encontro com as funções dos Deputados em participar da reforma estatal (BRASÍLIA, 2019).

Respectivamente, a ideia de destinar verbas da união para os municípios traz uma visão um pouco preocupante na responsabilidade fiscal dos mesmos, já que com abertura de receita estima-se um possível endividamento. O Senador Márcio Bittar, atualmente o relator da PEC garante a austeridade fiscal perante deliberação pautada, entretanto é necessário uma rigidez e fiscalização também de servidores públicos, onde a competência de anistiar infrações se deve aos Entes Federados (MASSON, 2019).

Se há uma dúvida quanto ao modo de controle fiscal seria a de qual instituição irá regular essa fiscalização. Existe a estimativa da criação de um Conselho Fiscal da República, onde tal instituição manteria um vínculo com os estados e municípios, entretanto, há a hipótese do conselho se tornar um órgão político e consequentemente afogar a administração em caminhos ativistas.

Assim, reveste-se de particular importância analisar qual o motivo que a PEC trás em extinguir municípios com menos de cinco mil habitantes, não teriam esses municípios a capacidade de auto sustento levando em consideração a produção agrícola e a base tributária urbana? Dado esse que foi colocado recentemente na Comissão de Direitos Humanos pelo Consultor da Confederação Nacional de Municípios. A organização financeira destinada às prefeituras não apenas depende dos seus valores internos, o Brasil possui mais de 5.000 municípios, logo os valores destinados da união exigem fiscalização de improbidade 
administrativa (SOUZA, 2018).

Perante os dados apresentados pela proposta de Emenda à Constituição surge a maneira sistemática de organização: "A defesa da coisa pública vem sendo realizada nas democracias modernas em dois níveis distintos: o nível político e o administrativo" (CHIAVENATO, 2018). Conforme mencionado pelo autor, as divisões organizacionais entre política e administração percorrem três possíveis formas de controle público. Administração pública patrimonialista, burocrática e gerencial representa a evolução de coordenação estatal, logo, a objetividade do novo pacto federativo deve-se atentar em não oscilar no ordenamento da gestão e evitar os moldes do regime patrimonial e burocrático.

No Brasil, há a incrível quantidade de municípios, instituições e Estados extremamente descentralizados, isso requer uma legislação rígida perante questões de corrupção, nepotismo e improbidades, pois assim como Riker (1975) comenta, não é suficiente apenas aplicar a estrutura constitucional, mas é importante entender as forças do poder político. Dado que a extinção de alguns municípios e posteriormente anexando a outros possa ser uma medida boa de corte de gastos, logo, a fiscalização desses pequenos municípios são duvidosas. Conforme explicado acima, atenta-se a PEC 188/2019 uma alternativa de melhora na educação, saúde, esportes, já que será destinada uma grande verba orçamentaria da união, o cerne da questão está justamente na forma de como será administrada pelas prefeituras.

Dentre inúmeros motivos, uma maior concentração de condições financeiras onde está a maior parte do povo brasileiro é de grande valia para evitar a desigualdade e desemprego:

[...] Ressalte-se que outro problema agravou a situação: embora tenha descentralizado recursos, a Constituição não criou um mecanismo de transição para estados e municípios construírem a capacidade de absorver as atividades de educação e assistência social que Ihes foram destinadas pela nova Carta. (COSTIN, 2010)

O entendimento baseia-se na oportunidade de os municípios oferecerem aos cidadãos uma melhor qualidade de vida, não obstante a contribuição da união ou do Estado como um todo. A autora deixa claro que mesmo o processo de descentralização causado pela Constituição de 88 , a proporcionalidade dos municípios com os demais entes no quesito de orçamentos para regular necessidades básicas da maior parte da população brasileira não foi declarada.

Nesse ritmo, gradativamente irá ultrapassar o modelo de administração gerencial, exatamente como aconteceu no burocrático onde em 1930 as pressões modernizantes exigiam a formulação de um Estado mais preocupado com o povo. Logo, como já foi colocado diversas vezes, existe uma dicotomia inseparável entre política e administração (KEINERT, 2007). Logo, é que com a evolução da política e a administração, fica cada vez mais fácil entender o processo de descentralização, pois, dividindo as funções para diversas instituições, um entendimento menos burocrático prevalece no cotidiano das pessoas.

É importante expor que devido a pandemia em 2020, causada pelo corona vírus, a proposta do novo pacto federativo foi um pouco desidratada, em razão dos novos gastos com as medidas econômicas e aumento de investimento em vários setores. Entretanto, no andamento da luta contra o vírus, deve-se dar continuidade ao enfrentamento e a segurança da população, consequentemente haverá despesas no futuro, 
dessa forma, a administração a posteriori terá que unificar as despesas. O investimento em educação e na saúde terá que ser prioridade, o âmbito privado deverá seguir sem interrupções, e as instituições bem como as máquinas públicas devem prosseguir com esforço e eficiência.

No caso de inflar a dívida pública, possivelmente pós pandemia, logo nas distribuições da vacina para toda a população, é normal acontecer um aumento vendas no comércio privado, mas também um aumento nos preços de mercadorias, bem como o gasto e déficit no cenário estatal. Diversos estudiosos da economia, sabe driblar e elaborar estratégias para solucionar os mais grandes problemas financeiros, uma das alternativas para a quitação da dívida pública está em vender estatais:

A ideia de que se poderia abater dívida pública com a venda de propriedade estatal já era apontada por Adam Smith (1937): “Em todas as monarquias da Europa, a venda das terras do rei produziria uma grande soma de dinheiro, a qual, se aplicada ao pagamento da dívida pública. (NUNES et al., 1998)

Importante, a venda de estatais torna-se delicada nesse momento, pois qualquer erro cometido será refletido em mais prejuízos para o Estado, a administração em geral deve focar na distribuição de competências, de acordo como está previsto na nossa constituição, mantendo a soberania e encontrando a melhor forma de fugir da crise.

\section{Aspectos da administração gerencial na PEC 188}

A princípio, define-se administração gerencial como aquela em que é aplicado aspectos modernos na máquina pública, onde o método é executado diretamente no arcabouço estatal e servidores. A administração gerencial visa a melhoria estatal, bem como o melhor plano de administração possível, o diferenciando da administração burocrática, logo, vários aspectos foram incluídos nessa proposta com o passar dos anos, pois a mesma segui um dos três pilares da ciência, onde os autores Bernades et al. (2009) determinam como "Paradigma da Complexidade".

Logo após a administração gerencial, foi exigido pelo povo mudanças, e dessa forma se concretizou a formação da administração gerencial com os seguintes aspectos:

(...) (1) descentralização do ponto de vista político, transferindo recursos e atribuições para os níveis políticos regionais e locais; (2) descentralização administrativa, através da delegação de autoridade para os administradores públicos transformados em gerentes crescentemente autônomos; (3) organizações com poucos níveis hierárquicos ao invés de piramidal; (4) pressuposto da confiança limitada e não da desconfiança total; (5) controle por resultados, a posteriori, ao invés do controle rígido, passo a passo, dos processos administrativos; e (6) administração volta-da para o atendimento do cidadão, ao invés de auto-referida. (PEREIRA, 1996)

Adentrando no novo PEC 188, podemos notar o primeiro aspecto citado por Bresser, descentralização do ponto de vista político, logicamente essa atribuição de transferência de recursos para os níveis regionais e locais de certo modo deveria ser comum no Estado brasileiro, entretanto a máquina pública está inflada com a concentração de recurso em grandes capitais.

Descentralizando de forma administrativa, também garantirá ao aparelho estatal o compartilhamento de fiscalização, possuindo uma dupla interação, o Estado e a pessoa jurídica, e com esses dois primeiros aspectos, a administração gerencial foi se tornando realidade, e é possível a visualização de 
pequenos fragmentos desse modelo em órgãos públicos, estatais e órgãos privados. E o resultado de todo esse processo é um sistema federalista completo com total base na constituição, ressaltando-se estipular a soberania do Estado com uma possível crise econômica, a soberania deve-se manter intacta para o bom funcionamento da nação.

O sistema de governo federalista está pautado na Constituição Federal, onde no art.60 dispõe sobre a proibição da abolição do sistema via emenda constitucional, portanto a junção das entidades federativas que por consequência fazem parte do federalismo considera-se cláusula pétrea. Podemos identificar outras formas de Estado, são elas: Federação, Confederação e Estado Unitário. Federação é o sistema adotado pelo Brasil, onde há a descentralização política, a definição teórica se daria como "a reunião, feita por uma Constituição, de entidades políticas autônomas unidas por um vínculo indissolúvel" (MASSON, 2019). Confederação é o sistema onde as entidades soberanas são os Estados nacionais, e diferentemente da federação, estes possuem um vínculo de dissolubilidade, ou seja, podem se separar a qualquer momento, o Estado Unitário se caracteriza principalmente pela centralização política (MASSON, 2019).

O pacto federativo também se torna essencial para manter uma relação entre os entes, logo, há a necessidade de se destinar competências para cada entidade. Tais competências estão espalhadas na constituição, destarte, falaremos de artigos que serão mudados caso a aprovação do Novo Pacto Federativo. No capítulo IV da constituição se dá as competências e atribuições administrativas aos municípios, a PEC 188 altera o artigo 29-A para uma redação que coloca os servidores inativos e pensionistas à mercê dos percentuais, relativos ao somatório da receita tributária (BRASÍLIA, 2019).

A mudança feita nesse artigo demonstra a manutenção financeira feita pelo Estado de forma a confirmar o princípio de uma administração gerencial, onde a descentralização fica ainda mais evidente uma vez que a transparência fiscal e a fiscalização prometem uma estrutura organizada que será regulada por um órgão da união.

Fica evidente, diante dessas informações que o processo de descentralização fomenta o Estado a utilizar de uma administração mais gerencial fazendo com que a população fique por dentro do sistema. A proposta é se adaptar a necessidade atual, visando aspectos atuais como a pluralização da ideia de eficiência perante a população.

\section{DISCUSSÃO TEÓRICA}

Essa pesquisa focou em demonstrar a importância da administração na federação brasileira, bem como analisar a partir do novo Pacto Federativo o processo de evolução do sistema, mesmo que em síntese não se tome a decisão mais apropriada, pois, levando em consideração a complexa estrutura político econômica é decerto que o processo será lento. O resultado obtido a partir do problema foi o levantamento de estruturas de administrar, buscando entender a particularidade de cada sistema, órgão ou instituição, dado que, tanto a União, Estados Membros e Municípios possuem suas especificidades.

O embasamento sugere da premissa de obter um sistema calcado em gerência periódica, Weber (citado por CHIAVENATO, 2018) deixa claro que a administração é moldada para atribuição do interesse 
coletivo, onde os entes se envolvem de maneira a não infligir a autonomia dos mesmos. Eis que o Estado tem direito de legislar e tributar os cidadãos, são essas medidas excepcionais que devem ser seguidas, entretanto observa-se por meio da administração a possível irregularidade que exista nestes fatores, ou seja, o ativismo judicial praticado pelo Supremo Tribunal Federal, ou a aprovação pela câmera dos Deputados e o Senado do aumento do fundo eleitoral, onde esse dinheiro possivelmente sairá dos tributos.

Esses gastos desnecessários acabam por gerar dificuldades na economia brasileira, pois, como todos sabemos a inflação é em muitas vezes gerada por déficits públicos (NETTO et al., 1983). Em diversas localidades do Brasil a porcentagem do IPTU terá reajuste, sob alegação do aumento da inflação no país. Como exemplo temos as cidades de Recife, Olinda e Jaboatão dos Guararapes em Pernambuco que em 2020 sofrerão reajustes de $2,54 \%$, indicadores que foram obtidos com pesquisa do IBGE através do IPCA. Logo, nota-se que na atual conjuntura administrativa e orçamentaria brasileira os processos econômicos passam por diversos trâmites, entre eles está a regulação de impostos e gastos.

A conclusão a tirar aqui é a seguinte: o sistema administrativo como um todo, e não se fala apenas na questão econômica, mas, partindo do princípio da generalidade, pode-se observar que o bom funcionamento do Estado se orienta no que seria três pilares. Tais pilares, por exemplo, se definiriam como: a deformação no sistema brasileiro de distribuição de renda, especificamente o da união, a má gestão pública no que diz respeito a organização das instituições, onde as fundações e empresas de economia mista também se enquadram e por fim o respeito as normas presentes na Constituição Federal. Na tabela 1 nota-se uma análise cronológica dos tributos cobrados pelos entes federativos.

Tabela 1: Percentual de Tributos dos Entes Federados.

\begin{tabular}{l|l|l|l|l|l|l|l|l|}
\hline Ente Federativo & $\mathbf{2 0 1 0}$ & $\mathbf{2 0 1 1}$ & $\mathbf{2 0 1 2}$ & $\mathbf{2 0 1 3}$ & $\mathbf{2 0 1 4}$ & $\mathbf{2 0 1 5}$ & $\mathbf{2 0 1 6}$ & $\mathbf{2 0 1 7}$ \\
\cline { 2 - 9 } $\begin{array}{l}\text { União } \\
\text { Estados }\end{array}$ Municípios & $69,01 \%$ & $69,98 \%$ & $69,05 \%$ & $68,93 \%$ & $68,46 \%$ & $68,32 \%$ & $68,37 \%$ & $68,02 \%$ \\
\cline { 2 - 10 } & $25,47 \%$ & $24,49 \%$ & $25,16 \%$ & $25,29 \%$ & $25,47 \%$ & $25,45 \%$ & $25,45 \%$ & $25,72 \%$ \\
\hline
\end{tabular}

Nota-se que os municípios dotam de menor porcentagem tributária, característica que é própria de pouco desenvolvimento. Destarte, as desigualdades regionais são consequência do não cumprimento dos três pilares, há de se dizer que o Brasil tem uma federação assimétrica no que diz respeito a questões socioeconômicas (MASSON, 2019). Conforme explicado acima, a reforma no pacto federativo deve ser analisada com objetivo de resolver questões que estão em déficit, para que assim o nível de detalhamento fique o mais raso possível, e os problemas com um grau de complexidade menor fiquem suscetíveis ao planejamento gerencial.

\section{CONCLUSÕES}

O desenvolvimento desta pesquisa possibilitou uma análise mais metodológica para assim entender o processo de administração pública aos moldes da forma de governo federalista, dessa forma objetiva-se diversas reflexões e questionamentos acerca da política pública brasileira e da forma como é distribuída a competência de regular orçamentos e finanças. De modo geral, a descentralização precisa ser regulamente modificada atendendo as necessidades da população por meio das instituições de cunho social e entidades 
jurídicas. Em amplitude a reforma deve ser feita em todos os âmbitos, pois, quando se fala em situações econômicas e administrativas as consequências não ficam restritas apenas a caso especifico.

O real objetivo é conseguir por meio de conhecimento tornar a administração pública cada vez mais perfeita, atendendo aos anseios dos habitantes que sãos os que mais sofrem com a burocratização de políticas pautadas em desorganização administrativa e corrupções. Entretanto não é necessário apenas tomar medidas administrativas, no âmbito judiciário e executivo se torna imprescindível a responsabilidade em tentar sempre agir dentro dos parâmetros de imparcialidade, não tomando partido sobre decisões estritamente públicas.

Dada à importância do tema, fica claro que é indispensável a produção de artigos que visem a melhoria administrativa no âmbito púbico, onde se torna necessário tecer críticas construtivas sobre toda forma de política, uma vez que o sistema é falho e muitas vezes criações de leis são feitas com o intuito de centralizar o Estado, por exemplo a lei aprovada para aumentar a verba campanha política.

Desta forma, a manutenção diária das reformas permite a visualização sistemática de falhas no sistema, perfazendo um caminho de evolução na democracia e cada vez mais aproximando os cidadãos dos assuntos públicos já que é esse o verdadeiro sentido de fazer política.

Com a Constituição de 1988, o Brasil adotou mais equanimidade e equilíbrio em todos os aspectos, logo estudos como esse que apontam as lacunas a serem preenchidas são de extrema importância no âmbito acadêmico e na realidade do país. Logo o estudo mostra a importância da relevante forma de agir entre órgãos intergovernamentais e os internos nacionais, pois a evolução estatal não está centralizada a um único território, é muito lógico criar interações com todas as culturas e nações.

O sistema de governo do Brasil possui uma complexidade enorme, com o passar dos anos é visível que as organizações tendem a expandir, Bernades et al. (2009) citam esse fenômeno como "Paradigma da Complexidade". Trata-se da interação que possui os organismos de um ser vivo, o mesmo acontece com o federalismo, gradativamente os órgãos públicos e privados vão criando um vínculo jurídico inseparável, de modo que a sensação de um paradigma é criada, mas existem três aspectos para visualizar e entender melhor esse fenômeno:

[...] o mundo é compreendido como horizonte de realidades mais vastas; a sociedade, o conhecimento e o ser humano são vistos como um sistema aberto [...] A complexidade é chamada de pensamento sistêmico novo paradigmático. Esse pensamento está alicerçado em três pressupostos: o da complexidade, da instabilidade e da intersubjetividade. (BERNADES et al., 2009)

Portanto, estipula-se com esses três aspectos o mais importante deles, a instabilidade, ressaltandose que esse aspecto é atribuído a jeito de mudança que possui o organismo vivo, ou seja, a nossa federação, nosso Estado como um todo. Dessa forma, entendendo a instabilidade e atribuindo ao processo de mudança a melhor forma de resolver o problema, será solucionado não todos os problemas, pois é impossível, mas a evolução de um Estado cada vez mais.

A intersubjetividade vem após a consciência de mudança, pois é nela que será atribuída a ação, onde o paradigma da complexidade será entendido. Isso é ciência, estudiosos da física, química e diversas áreas mantem esse trabalho, entendem a instabilidade das coisas, do mundo, para só depois tomar medidas e 
ações de solução do problema, logo, em consequência, se não houver ação não tem mudança e: Se torna imutável o sistema quando não se propõem mudanças, onde a alteração de estruturas políticas garantirá para a nação direitos sociais que representam a participação política e repartição de riquezas (SANTOS et al., 2014). Cabe aos profissionais, políticos e diversos funcionários do nosso Estado cumprir esse processo na ordem com responsabilidade, esse passo a passo terá de ser aplicado agora, onde se vive uma pandemia causado por um vírus que devastou a saúde de vários e criou um paradigma da complexidade nas finanças públicas e privadas.

O sistema federalista bem como a gênese de um processo administrativo deve ser tratado com semelhança, onde possuirá em todo o seu corpo administrativo hierarquia e profissionalismo, exemplo a distribuição de riquezas em todo o território nacional. Há de saber que essa distribuição deve ser feita de forma responsável, pois é um elemento de instabilidade, será necessário a hierarquização de competências para que toda distribuição esteja dentro dos conformes da lei e da necessidade de cada estrutura, e logo mais será necessário o profissionalismo dos órgãos a qual foi destinado a riqueza, e não menos importante a responsabilidade do servidor que administrará.

Portanto, federalismo entende-se como um organismo vivo em sua totalidade, e possui suas subdivisões, que são de suma importância para o funcionamento do todo, tais fragmentos se relacionam com hierarquização de funções relevantes e não relevantes. O federalismo é o corpo humano, e tudo que possui dentro do corpo humano é o Estado, cada célula do corpo humano é um órgão estatal, uma capital, um município.

Finaliza-se este estudo com a lição de seguir os três passos para a continuidade de uma nação grande e vasta, possuindo a plena consciência e aplicando em todas as áreas obterá êxito o federalismo, complexidade, instabilidade e intersubjetividade.

\section{REFERÊNCIAS}

BRASIL. Constituição da República Federativa do Brasil: promulgada em 5 de outubro de 1988. 4 ed. São Paulo: Saraiva, 1990.

BRASÍLIA. Ajuste fiscal do 'Plano Mais Brasil' contrapõe governo e especialistas na CDH. Brasília, 2019.

BRASÍLIA. Proposta de Emenda à Constituição n 188, de 2019. Brasília, 2019.

BERNADES, A. R. O.; AMBONI, N.. Estratégias de Gestão: Processos e funções do Administrador. Rio de Janeiro: Elsevier, 2009.

CHIAVENATO, I.. Administração Geral e Pública. Barueri: Manole, 2018.

CASTOR, P. C. K.. Autonomia Municipal como fator de desenvolvimento local. Dissertação (Mestrado) - Centro Universitário das Faculdades Associadas de Ensino, Curitiba, 2008.

COSTIN, C.. Administração Pública. Rio de Janeiro: Elsevier, 2010.
DURKHEIM, É.. Lições de Sociologia. São Paulo: WMF Martins Fontes, 2016.

EVANS, M.. Studying the New Constitutionalism: Bringing Political Science Back In. British Journal of Politics and International Relations. FILHO, M. P.. A nova administração pública: Profissionalização, Eficiência e Governança. São Paulo: DVS, 2001.

FERNANDES, A. S. A.; ARAÚJO, S. M. V. G.. A criação de municípios e a formalização de regiões metropolitanas: os desafios da coordenação federativa. Revista Brasileira de Gestão Urbana, v.7, n.3, 2015. DOI:

https://doi.org/10.1590/2175-3369.007.003.A007

GIL, A. C.. Como elaborar projetos de pesquisa. 6 ed. São Paulo: Atlas, 2017.

KEINERT, T. M.. Administração pública no Brasil: Crises e mudanças de paradigmas. São Paulo: ANNABLUME, 2007.

LAKATOS, E. M.; MARCONI, M. A.. Fundamentos de metodologia científica. 8 ed. São Paulo: Atlas, 2017. 
MASSON, N.. Manual de direito constitucional. 7 ed. Salvador: Juspodvim, 2019.

NETTO, D.; MODIANO, E.. Inflação e controle do déficit público: análise teórica e algumas simulações para a economia brasileira. PUC-Departamento de Economia, 19. 1983.

NUNES, R. C.; NUNES, S. P. P.. Privatização e ajuste fiscal: a experiência brasileira. Planejamento e Políticas Públicas, n.17, p.171-213, 1998.

OLIVEIRA JUNIOR, R. R.; TAVARES, R. S.. Pacto Federativo Brasileiro: $O$ impacto no Desenvolvimento dos municípios com estudo de caso de Belford Roxo/RJ. Revista Controle Social e Desenvolvimento Territorial, v.3, n.3, 2018.
PEREIRA, L. C.. Da administração pública burocrática à gerencial. Revista do Serviço Público, v.47, n.1, p.07-40, 1996. DOI: https://doi.org/10.21874/rsp.v47i1.702

PRODANOV, C.; FREITAS, E.. Metodologia do trabalho científico: Métodos e Técnicas da Pesquisa e do Trabalho Acadêmico. Novo Hamburgo: FEEVALE, 2013.

RIKER, W.. Federalism. In: GREENSTEIN, F.; POLSBY, N.. Handbook of Political Science. 1975.

SANTOS, A.; MUNIZ, E.. A aplicabilidade do princípio do não-retrocesso aos direitos sociais. Brasília: Vestnik, 2014.

SOUZA, J. C.. Descentralização. JUS, 2018.

A CBPC - Companhia Brasileira de Produção Científica (CNPJ: 11.221.422/0001-03) detém os direitos materiais desta publicação. Os direitos referem-se à publicação do trabalho em qualquer parte do mundo, incluindo os direitos às renovações, expansões e disseminações da contribuição, bem como outros direitos subsidiários. Todos os trabalhos publicados eletronicamente poderão posteriormente ser publicados em coletâneas impressas sob coordenação da Sustenere Publishing, da Companhia Brasileira de Produção Científica e seus parceiros autorizados. Os (as) autores (as) preservam os direitos autorais, mas não têm permissão para a publicação da contribuição em outro meio, impresso ou digital, em português ou em tradução. 